\title{
O CASO DO AMIANTO: OS LIMITES DAS SOLUÇÕES LOCAIS PARA UM PROBLEMA DE SAÚDE GLOBAL
}

Kathia Martin-Chenut

Pesquisadora do CNRS (Centre National de la Recherche Scientifique), França, UMR DRES (CNRS/UNISTRA) - Equipe SER. Paris, França.Email < kathiamc@orange.fr >

Jânia Saldanha

Professora do Programa de Pós-Graduação em Direito e do Departamento de Direito da UFSM - Universidade Federal de Santa Maria. Santa Maria, RS. Brasil.

Email<janiasaldanha@gmail.com>

http://dx.doi.org/10.1590/ 0102-6445141-170/98

O direito, embora não acompanhe sincronicamente a sociedade, a economia e a política, sofre uma recomposição na sua paisagem jurídica. O espaço se desestatiza pela internacionalização do direito, pela descentralização e privatização das fontes. O tempo se desestabiliza, as leis durando enquanto estiverem em sintonia com a realidade social, em constante mutação. $\mathrm{E}$ a ordem se deslegaliza pelo ganho de força das fontes não legislativas (Delmas-Marty, 2004, p. 77) e da autorregulação. As categorias jurídicas são metamorfoseadas sob o impacto de novos conceitos como o de desenvolvimento sustentável (Martin-Chenut e Quenaudon, 2015). O desenvolvimento deixa de se confundir com crescimento para englobar objetivos amplos como o de um meio ambiente saudável, de condições de trabalho e de vida dignos ou ainda de segurança dos indivíduos contra ameaças globais.

O contencioso em torno da utilização do amianto, que é objeto deste artigo, deve ser analisado levando em conta esse novo cenário, que compreende a complexidade da desnacionalização dos direitos, a desterritorialização das formas 
institucionais e a descentralização das formas políticas do capitalismo, além da realocação geográfica dos investimentos produtivos e das mudanças radicais na divisão internacional do trabalho (Faria, 2004, p. 60).

Fruto de uma primeira reflexão conjunta sobre os limites das respostas nacionais ao problema de saúde pública global ou "glocal"1, o artigo, inicialmente, apresenta a produção e o uso do amianto como problema de saúde pública "glocal", para depois analisar o contencioso que ele acarreta, insistindo em seus limites.

\section{Produção e uso do amianto: um problema de saúde pública "glocal"?}

$\mathrm{O}$ amianto ou asbesto identifica um grupo de minerais da variedade crisotila ou dos anfibólios (IARC, 2012). Esse grupo mineral apresenta como características físicoquímicas flexibilidade, resistência mecânica, baixa con-

142 dutividade térmica, boa capacidade de isolação térmica e acústica e possui similitude com o cimento e resinas, assim como estabilidade em ambientes de $\mathrm{pH}$ variável (Saldanha e Blatt, 2007).

Essas características particulares facilitaram o largo uso do mineral ao longo do século XX, fato que, inevitavelmente, despertou o interesse econômico de empresas e Estados. $\mathrm{O}$ uso industrial e comercial do amianto relaciona-se a cerca de 3 mil aplicações (IARC, 2012, p. 3). Do ponto de vista de sua utilidade, por exemplo, esse mineral se presta para produzir telhas onduladas, caixas d'água, tubos, placas de revestimento, isolantes térmicos e produtos de fricção como discos de embreagem, pastilhas e lonas de freios de veículos.

É inegável, portanto, que, em plena era da industrialização desenfreada, os derivados do amianto ocuparam um lugar importante nas matrizes produtivas desde a pas-

1 Neologismo com a contração das palavras global e local. 
sagem do século XIX para o XX (Saldanha e Blatt, 2007, p. 2). Por isso, durante os primeiros 75 anos, o amianto foi explorado, produzido e consumido pelos países industrializados da Europa. Entretanto, o Canadá e a ex-União Soviética foram os países que reuniram o monopólio de dois terços da produção mundial (Vogel, 2005) em boa parte do século passado. Na Rússia, logo após o fim da Primeira Grande Guerra, a necessidade de modernizar as redes ferroviárias requereu aumento da produção de amianto, a qual, na década de 1970, ultrapassa a do Canadá para, poucos anos depois, na década de 1990, experimentar queda relacionada à falta de organização das atividades industriais e à crise do setor de construção. Já o Canadá, passou de primeiro produtor mundial à condição de Estado que interditou totalmente, a partir de 2012, a produção de amianto. Contudo, esse país exemplifica a prática do duplo standard, que vigorou durante décadas no comércio mundial desse minério. Embora houvesse reduzido o consumo interno a quase zero, exportava $95 \%$ de sua produção para países da Ásia e da América Latina. Apesar de admitir seu caráter "prejudicial"², continuou exportando o minério como se ele não fosse nefasto quando exportado (Andeva, 2014). Durante anos, o Canadá foi o grande defensor e promotor do "uso controlado" do amianto, razão que inspira, ainda hoje, os países que o exploram.

No ano de 2005, a União Europeia proíbe a produção e o consumo do produto ${ }^{3}$. O banimento de seu uso decorreu da forte e longa pressão de organizações sindicais, de vítimas e representantes de vítimas que sofreram

\footnotetext{
2 "Não utilizamos o amianto no Canadá faz 30 anos porque sabemos que é bastante prejudicial". Apenas em 2015, o Santé Canada (Ministério da Saúde local) muda em seu sítio eletrônico a advertência sobre o uso do amianto dizendo: "Em caso de inalação, as fibras de amianto podem causar câncer e outras doenças". Essa recomendação altera a anterior que referia que o amianto quando "aspirado em grandes quantidades” seria nefasto à saúde (Canadá, 2015; Santé, 2015).

3 A França proíbe sua utilização desde 1997 (França, 2012).
} 
danos direta ou indiretamente. Contudo, ele não faz parte do passado. Além da Rússia, atualmente existem minas na África do Sul, no Brasil, no Cazaquistão, na China, no Zimbábue, entre outros. Os países em desenvolvimento que exploraram o minério ao longo do século XX receberam estímulos financeiros de empresas europeias para isso (Vogel, 2005, p. 2).

Estudos científicos demonstram ser o amianto causador de uma verdadeira "catástrofe sanitária", que produz danos de dupla face: (a) à saúde humana, por provocar doenças como asbestose (fibrose pulmonar); câncer de pulmão (tumor maligno); mesotelioma (tumor maligno de pleura e pericárdio; câncer lingual, laringe e ovário, faringe, estômago e cólon retal (IARC, 2012, p. 76) ${ }^{4}$; e (b) ao meio ambiente, tanto durante o curso de sua extração e produção quanto depois, no curso da gestão dos dejetos.

$144 \quad$ No Brasil, a Portaria $\mathrm{n}^{\circ}$ 9, de 7 de outubro de 2014, do Ministério do Trabalho e Emprego, Saúde e da Previdência Social, seguindo a linha do Centre International de Recherche sur le Cancer (CIRC), classificou o amianto, sob qualquer de suas formas, como um agente cancerígeno para humanos (Brasil, 2014). Contudo, há uma significativa diferença entre esse reconhecimento teórico e o que acontece na realidade. De fato, segundo o Boletim Epidemiológico Morbimortalidade de Agravos à Saúde Relacionados ao Amianto no Brasil, 2000 a 2011, elaborado pelo Centro Colaborador de Vigilância dos Agravos à Saúde Relacionados ao Trabalho, da Universidade Federal da Bahia UFBA (Centro Colaborador UFBA/ISC/Pisat, 2012), há uma assimetria entre os verdadeiros números do drama de

\footnotetext{
4 Pesquisa finalizada no ano de 2012 pelo Centre International de Recherche sur le Cancer (CIRC; em inglês, IARC) indica serem carcinogênicas todas as formas de asbestos ou amianto, incluindo a "acnolite, amosite, anthophyllite, chrysotile, crocidolite e tremolite" (IARC, 2015).
} 
saúde pública provocado pelo uso do amianto e os registros de morte que dele decorrem. Assim, os índices apresentados pelo Sistema de Informação sobre Mortalidade (SIM) não correspondem à catástrofe sanitária realmente existente. Isso se deve ao "recorrente sub-registro da relação das doenças e acidentes com o trabalho" (Centro Colaborador UFBA/ISC/Pisat, 2012), que se intensifica no caso do amianto em razão do longo espaço temporal superior a vinte anos - que medeia entre o uso desse minério e o início do aparecimento dos sintomas das doenças que ele provoca.

Enquanto alguns países da América Latina alteraram suas legislações internas e proibiram integralmente o uso do amianto, como Argentina, Chile, Honduras e Uruguai, outros, não apenas permitem, como experimentam crescimento na produção e consumo do mineral, o que tem provocado um significativo problema de saúde pública. Essa é a situação do México, que vive uma verdadeira epidemia de mesotelioma (Andeva, 2015; El País, 2014).

As fortes pressões econômico-políticas, de um lado, e a luta em defesa dos direitos humanos, de outro, compõem o quadro tenso desenhado no embate entre as posições contrárias e favoráveis ao uso do amianto, e que expressam, em verdade, a dupla face da globalização. A primeira é representada por uma sorte de atitudes contra-hegemônicas, expressas no denominado cosmopolitismo insurgente e em nome do "comum" em matéria de direitos humanos, vinculadas às posições dos atores nacionais e não nacionais contrários ao uso do minério. A segunda é representada por atitudes hegemônicas, expressas por meio dos localismos globalizados e dos globalismos localizados, ligadas aos defensores do uso controlado do amianto. 


\section{A interdição do amianto: resistência do cosmopolitismo subalterno}

Segundo a Organização Mundial da Saúde (OMS), cerca de cinquenta países proíbem completamente o amianto ${ }^{5}$. Esses países, bem como organizações não governamentais, tanto em nível nacional, a exemplo da Associação Brasileira dos Expostos ao Amianto (Abrea) e da Associação Baiana dos Expostos ao Amianto (Abea), como global, representada pela Ban Asbestos Network, cuja coordenação regional fica a cargo da Rede Virtual-Cidadã pelo Banimento do Amianto na América Latina (Abrea, 2015), quanto também a Association Nationale de Défense des Victimes de l'Amiante (Andeva, 2015), da França, são contrários ao uso controlado do amianto pelo fato de que os estudos científicos não determinam um índice mínimo em que seu manuseio e consumo não causariam danos à saúde e ao meio ambiente.

No Brasil, algumas empresas, voluntária ou compulsoria146 mente, caminharam e caminham em direção à abolição total do uso do amianto. Exemplo do primeiro caso foi a empresa Brasilit, controlada pelo grupo francês Saint-Gobain, que após o banimento na França em 1997, abandonou a antiga parceira Eternit e passou a investir em materiais substitutivos e defender a ampliação desse novo mercado (Brum, Cançado e Barrocal, 2005). Exemplo do segundo caso são as empresas Infibra e Confibra, que, em 2015, obrigaram-se, no âmbito de um Termo de Ajustamento de Conduta (TAC) firmado com o Ministério Público do Trabalho, a cessar a utilização do mineral como matéria-prima de seus produtos até $1^{\circ}$ de janeiro de 2017 (Ecodebate, 2015).

\footnotetext{
5 A saber: Argélia, Argentina, Austrália, Bahrain, Brunei Darussalam, Chile, Egito, os 28 Estados da União Europeia, Gabão, Honduras, Islândia, Israel, Japão, Jordânia, Kuwait, Moçambique, Noruega, Omã, Qatar, República da Coreia, Arábia Saudita, Servia, República das Seychelles, África do Sul, Suíça, Turquia e Uruguai (OMS, 2014). No Brasil, o Instituto Nacional do Câncer indica a proibição em 62 países (INCA, 2016).
} 
Outrossim, uma vez que o contato com o amianto se manifesta também no âmbito das relações de consumo, órgãos de defesa e proteção do consumidor têm atuado contra o uso do mineral, como é o caso do Instituto Brasileiro de Defesa do Consumidor (Idec, 2007). É evidente, assim, que o problema provocado pela exploração e uso do amianto transcende a esfera ocupacional, sendo uma ameaça à saúde pública e ambiental, pondo em risco os trabalhadores (tanto na extração, como na industrialização), consumidores, moradores em áreas próximas de minas e fábricas. A "exposição não ocupacional ou ambiental" refere-se a exposições domésticas, poluição do ar tanto no exterior como no interior de ambientes, entre outras, segundo a OMS (2014).

A Abrea, entidade decretada de utilidade pública em nível federal e estadual, pode ser considerada a principal organização brasileira que lidera a luta em favor da interdição total do uso do amianto no Brasil (Castro, Giannasi e Novello, 2003, p. 908). Os fundamentos dessa luta são confirmados pelo último relatório da OMS, que demonstra não existir, realmente, nenhum limite seguro de utilização do mineral.

Desse modo, questões estruturais vividas em diversos países e relacionadas aos problemas de saúde pública e ambiental têm estimulado e direcionado tomadas de posições público-institucionais em defesa desses dois bens comuns da humanidade, e contra a hegemonia da prevalência dos interesses econômicos como fim último. As campanhas nacionais e mundiais, patrocinadas sobretudo por atores privados com origem na sociedade civil, pressionam os Estados e as empresas privadas a abandonar a exploração e o uso do amianto. Esse desenho de participação política e militante pode ser decifrado no contexto das premissas do cosmopolitismo insurgente e subalterno, na dicção de Boaventura de Sousa Santos (2006). Em verdade, ele compõe um 
quadro de luta e resistência por iniciativa de múltiplos atores, movimentos e organizações como condição de possibilidade de afirmação de certos princípios e bens inseridos na noção de "comum" (Delmas-Marty, 2010, p. 207) da humanidade, que balizam as lutas transnacionais globalmente (Santos, 2006, pp. 437-41).

\section{A aceitação do uso controlado do amianto: localismo globalizado e globalismo localizado}

Inúmeros atores nacionais e não nacionais, fundados sobretudo em razões econômicas, assumem declarada posição em favor do uso controlado do amianto. Invocando marcos normativos internacionais, apegam-se, em primeiro lugar, à Convenção 162 da OIT (Organização Internacional do Trabalho), de 4 de junho de 1986, realizada em Genebra (Brasil, 1991), na referência que esse texto faz sobre o uso controlado do amianto crisotila. Ignoram, porém, que vinte 148 anos mais tarde, durante a $95^{\mathrm{a}}$ sessão da OIT, esse organismo internacional, alarmado pela morte de aproximadamente 100 mil trabalhadores por ano no mundo em razão do contato humano com esse mineral por motivos ocupacionais, aprovou a resolução, adotada em 14 de junho de 2006 (Bureau International du Travail, 2006), que decidiu: (a) pela supressão do uso futuro do amianto, bem como a identificação e a gestão correta do amianto "atualmente presente" para proteger os trabalhadores, evitar futuras doenças e mortes; e (b) que a Convenção 162 sobre o amianto não deveria servir para justificar ou aceitar o prosseguimento do uso do amianto.

Já do ponto de vista da legislação interna brasileira, os atores nacionais - públicos e privados - defensores da continuidade do uso do amianto invocam a Lei $\mathrm{n}^{\circ}$ 9.055/95, que dispõe sobre a extração, industrialização, utilização, comercialização e transporte do asbesto/amianto e derivados. Essa lei proíbe a exploração e uso do amianto "azul" e 
do amianto "marrom" ", permitindo apenas a realização de tais atividades com o amianto "branco" crisotila.

O Sumário Mineral de 2014 (DNPM, 2014), cujo ano base foi 2013, do Departamento Nacional de Produção Mineral do Ministério de Minas e Energia (DNPM), indica que o Brasil é o terceiro maior produtor de amianto, sendo precedido pela Rússia e pela China. O Cazaquistão se encontra em quarto lugar no ranking mundial. O Brasil, no ano em referência, conheceu um decréscimo de 4,51\% na produção, sendo 44,2\% dela destinadas ao mercado externo, cujo volume de exportação teve também 16,5\% de queda. Embora registre queda interna na produção de amianto, o Brasil passou do $5^{\circ}$ para o $3^{\circ}$ lugar no ranking mundial, dado que demonstra a prevalência de políticas estatais dirigidas e praticadas para preservar os interesses econômicos, em detrimento dos problemas de saúde e ambientais que o amianto provoca. Nesse sentido, dados fornecidos pela OMS indicam que, no mundo, 125 milhões de pessoas estão expostas ao minério por razões de trabalho, e o número de mortes causadas por ele atinge a cifra aproximada de 107 mil pessoas por ano (OMS, 2016).

O amianto brasileiro deriva da mina de Cana Brava, única lavra de crisotila em produção no território nacional e que está localizada em Minaçu, Goiás. É a grande senão a única - fonte de renda do município, cuja empresa exploradora é a Sama. Segundo o Sumário mineral do DNPM (2014), em 2013, foram investidos 6,34 milhões de reais no projeto para aquisição, reforma de equipamentos, inovações tecnológicas e de sistemas, infraestrutura, meio ambiente, saúde e segurança no trabalho.

Outros atores atuam ativamente em favor do uso do amianto. Originado com inspiração canadense, o Instituto Brasileiro de Crisotila (IBC, 2016), pessoa jurídica de

6 Anfibólios: actinolita, amosita, antofilita, tremolita. 
direito privado, reúne como parceiros as grandes empresas que comercializam o amianto e os produtos dele derivados. Coerente com essa premissa, seu Conselho Superior (IBC, 2016) é integrado por representantes de inúmeras empresas brasileiras e transnacionais como: Sama, Eternit e Isdralit. Registre-se que a empresa Eternit, considerada a maior fabricante de coberturas do Brasil, não apenas defende o uso controlado do amianto crisotila como também é a empresa controladora da Sama, a terceira maior produtora de crisotila do mundo. A condenação penal dos diretores da Eternit em processo que tramitou em Turim, como veremos em seguida quando discorreremos sobre o contencioso relativo ao amianto na Itália, não serviu de exemplo para que a empresa abandonasse o uso do amianto em seus produtos.

No Brasil, o IBC, com o suporte de todas as empresas "parceiras", é a instituição defensora do uso controlado do 150 amianto crisotila, fundando-se em pesquisas que patrocina. Uma de suas pesquisas afirma que "baixas exposições a crisotila não representam risco perceptível à saúde” (IBC, 2014). Contudo, essa conclusão contraria estudos mundiais que afirmam a inexistência de qualquer limite tolerável ao contato humano com o amianto. As grandes empresas envolvidas nesse nicho de mercado sustentam, primeiramente, que o amianto não é um problema de saúde pública, mas sim ocupacional. E, segundo, que o amianto permitido no Brasil é o menos agressivo, bem como já foi desenvolvida tecnologia capaz de tornar o processo de extração e industrialização ${ }^{7}$ seguro aos trabalhadores.

Pesquisadores da Unicamp (2010, pp. 28-29), no estudo Avaliação do impacto econômico da proibição do uso do amianto na construção civil, foram contrários às teses favoráveis ao

7 São exemplos disso: (a) despoeiramento; (b) recorte de telhas em cabines enclausuradas; (c) moinhos de cacos nas fábricas; (d) treinamento e proteção individual; (e) moldagem de pequenas peças feitas a úmido. 
uso controlado do amianto de que: (a) fibras alternativas seriam viáveis, já estariam em processo avançado de substituição e que os efeitos negativos seriam apenas ao segmento do amianto, os quais poderiam ser compensados com políticas de apoio a Minaçu, a região atingida; (b) os efeitos negativos poderiam ser compensados com a ampliação dos investimentos e dos empregos em tecnologias alternativas; e (c) os efeitos sobre os preços dos produtos alternativos não seriam significativos e esses poderiam custar no máximo $10 \%$ mais caro do que os produtos produzidos com amianto. A conclusão é taxativa: "A forma mais eficaz de se obter um controle efetivo sobre os riscos representados pelo amianto é por meio da proibição da extração, do transporte, da industrialização, da comercialização e da utilização do amianto em todas as suas formas no território brasileiro" (Unicamp, 2010, p. 30).

Seguramente, os fortes interesses econômicos de espectro mundial, que envolvem interesses públicos tanto dos poucos países produtores de amianto, quanto das grandes empresas transnacionais que exploram a extração, produção e fabricação dos seus derivados, exercem um papel fundamental na manutenção da tese do uso controlado. A estratégia utilizada pelo IBC nos faz pensar no Comité Permanent Amiante (CPA), da França, promotor do uso controlado do amianto e que, em 2005, teve seu papel analisado em um relatório do Senado daquele país, que lhe consagrou uma sessão cujo título evocador era: "O Estado anestesiado pelo lobby do amianto” (França, 2005). Diante de estudos científicos que comprovam a nocividade das fibras de amianto, não é possível sustentar que o mesmo não ofereça risco algum à saúde humana e ao meio ambiente.

A manutenção de uma indústria que gera milhões de dólares anualmente, para poucos, integra a lógica do processo de globalização hegemônica que apresenta uma dupla face (Santos, 2006; Saldanha e Blatt, 2007). A primeira 
pode ser identificada como um "localismo globalizado", porque a lógica do uso controlado, assumida pela lei federal brasileira, tem origem na cruzada mundial pró-amianto, desenvolvida por vários anos pelo Canadá, que, como visto, há mais de trinta anos deixou de consumir internamente esse mineral. Com efeito, sempre que determinada lógica particular ou ator pode ser identificado como vencedor de uma luta pela apropriação de determinado saber ou prática, capaz de impor padrões de negociação, de produção, de inclusão ou de exclusão, estará presente o localismo globalizado. E, na medida em que essas lógicas ou padrões são "exportados", provocando um impacto muito específico em legislações ou ações de outros países, emerge a outra face da globalização hegemônica, qual seja, a de um globalismo localizado por, amiúde, determinar, desintegrar e desestruturar certas condições locais para, depois, reestruturá-las sob a forma de uma "inclusão subalterna" (Santos, 152 2006, p. 434).

Justamente por isso e diante das inércias dos Poderes Executivo e Legislativo, é que a problemática do amianto tem sido judicializada.

\section{A judicialização do caso do amianto em perspectiva comparada}

O embate entre defensores e detratores do uso controlado do amianto, presente em inúmeros países, tem sido transformado em demandas judiciais perante os sistemas de justiça nacionais, com a finalidade seja de questionar as leis internas que autorizam a sua produção e uso, seja para que as vítimas ou suas famílias reivindiquem reparação dos danos sofridos. Tais demandas são fundadas em textos constitucionais e internacionais relativos aos direitos humanos, que protegem, direta ou indiretamente, o direito à saúde e ao meio ambiente.

$\mathrm{O}$ ritmo e as respostas que os sistemas de justiça têm dado a tais demandas dependem da complexidade do sis- 
tema processual e da estrutura da própria justiça. Abordaremos, neste artigo, o exemplo brasileiro para, em seguida, compará-lo aos exemplos francês e italiano.

\section{O exemplo brasileiro}

Os conhecidos danos à saúde individual e coletiva das pessoas, bem como os danos ao meio ambiente produzidos pela exploração, produção e consumo do amianto crisotila até hoje não foram suficientes para deflagrar uma tomada de atitude do Congresso Nacional brasileiro para derrogar inteiramente a lei interna que permite a exploração e consumo dos produtos que têm por base o referido minério. Tampouco têm sido suficientes as normativas internacionais protetivas da saúde e do meio ambiente, como a já mencionada Resolução da OIT de junho de 2006, que indica claramente a posição contrária da instituição quanto ao uso do amianto e em favor da saúde e da segurança no trabalho; ou, no âmbito interamericano, do Protocolo de San Salvador de 1988, relativo aos direitos econômicos, sociais e culturais, cujo conteúdo normativo o Brasil está obrigado, convencionalmente, a respeitar.

Contudo, do ponto de vista do direito interno, ainda que a Constituição Federal (CF) atribua a tais direitos o status de direitos fundamentais, há no país uma verdadeira "diáspora legislativa" na matéria. Isso se deve à estrutura do Estado brasileiro, que possibilita competência concorrente para legislar sobre saúde e meio ambiente. Tal dispersão também ocorre quanto ao quadro legislativo relativo ao uso do amianto. Este $^{8}$, como consequência da combinação de competências enumeradas para a União (CF, art. 21 e 22) e para os municípios (CF, art. 30), e residual para os estados (CF, art. 25, parágrafo $1^{\circ}$ ), exclusivas ou privativas

8 Uma tabela da Abrea (2011) retrata o quadro de proibição do amianto no Brasil, seja por leis estaduais ou municipais. 
(delegáveis - CF, art. 22, parágrafo único), áreas de atuação comuns e competências legislativas concorrentes da União e estados. Mas a dispersão de competências é só parte do problema. Seria totalmente enganador pensar que a resolução dessa diáspora repousaria apenas em uma uniformização legislativa nas esferas estadual e municipal. Uma solução desse cariz não enfrentaria o problema central - a exploração e o uso do amianto e os danos que produz - que está já à espera de uma resposta do Poder Judiciário. Nesse sentido, o que ainda permanece sem resposta é se a Lei $\mathrm{n}^{\circ}$ 9.055/95 respeita a Constituição Federal e as convenções protetivas dos direitos humanos.

$\mathrm{O}$ tangenciamento do problema puramente às questões de forma legislativa ficou patente no objeto e, depois, nas decisões proferidas, nas duas primeiras ações envolvendo o amianto que chegaram ao Supremo Tribunal Federal (STF) no ano de 2001. As ADIs (ações diretas de incons154 titucionalidade) $\mathrm{n}^{\circ} 2.396$ e $\mathrm{n}^{\circ} 2.656$ foram ajuizadas pelo governador do Estado de Goiás contra, respectivamente, a Lei $\mathrm{n}^{\circ}$ 2.210, de 2001, do Estado do Mato Grosso do Sul, e a Lei $\mathrm{n}^{\circ}$ 10.813, de 2001, do Estado de São Paulo. Assim, o STF, sob a alegação de que a análise das questões técnicas relativas ao uso do amianto fugia de sua competência, apenas reafirmou ter competência em termos de legalidade constitucional, decidindo que não caberia a ele dar a última palavra concernente às propriedades técnico-científicas do amianto, já que sua atuação estaria restrita apenas à verificação do contraste entre a lei ordinária e o parâmetro constitucional" (STF, 2003). Desse modo, se limitou a declarar a inconstitucionalidade da lei estadual apenas porque o Mato Grosso do Sul teria extrapolado sua competência concorrente para legislar sobre produção e consumo (CF, art. 24, IV), proteção ao meio ambiente e controle da poluição (CF, art. 24, VI), proteção e defesa da saúde (CF, art. 24, XII; STF, 2003). Na medida em que a Lei $\mathrm{n}^{\circ} 9.055 / 95$, ainda 
em vigor, permite produção e venda do amianto crisotila, a Suprema Corte entendeu que as legislações estaduais extrapolaram a sua competência. Então, o vício de inconstitucionalidade reconhecido foi apenas a existência de inconstitucionalidade formal (STF, 2003).

Em 30 de novembro de 2004, a Confederação Nacional dos Trabalhadores na Indústria promoveu a ADI n 3.357 questionando a constitucionalidade da Lei $\mathrm{n}^{\circ} 11.643$, de 2001, do Rio Grande do Sul, que proíbe o uso de amianto, sob o argumento de que esse texto legislativo viola o princípio da livre-iniciativa previsto no artigo 170 da CF e por invasão de competência da União. O então Ministro Relator Ayres Britto foi o primeiro a votar nessa ação, entendendo que a Carta Constitucional deve ser aplicada de forma imediata. Afirmou que, "por se cuidar de competência legislativa, igualmente primária, a União não precisa esperar pelos Estados e os Estados não precisam esperar pela União". Completou dizendo que "Se a União resolve tomar a dianteira do ato de legislar pode fazê-lo, mas há de se conter na produção de normas gerais". Segundo ele, "Como as normas gerais não são plenas e as normas suplementares não são plenas, é dessa adição das normas gerais da União e suplementares dos estados que se alcança a plenitude normativa, que se perfaz em torno de um bem jurídico de matriz constitucional”. Para Ayres Britto, os bens jurídicos contidos na CF, como meio ambiente, saúde, entre outros, recebem uma constante proteção normativa, o que decorre da simples verificação de "serem ambos os bens jurídicos classificados como fundamentais" (STF, 2012b, p. 6).

Em 6 de agosto de 2007, a Confederação Nacional dos Trabalhadores na Indústria ajuizou perante o STF outra ADI, de $n^{\circ} 3.937$, questionando a constitucionalidade da Lei $\mathrm{n}^{\circ}$ 12.684, de 2007, do Estado de São Paulo, cujo texto proíbe o uso de todo e qualquer tipo de amianto nesse estado. Nessa demanda (CNTI, 2007), a Confederação apresentou 
uma alegação de natureza substancial, qual seja, a da compatibilidade do uso do amianto crisotila com a saúde humana e a já conhecida alegação de natureza formal de inconstitucionalidade do texto estadual porque essa legislou sobre normas gerais de produção e de consumo, cuja competência é do legislador federal. No âmbito dessa ação, nos dias 24 e 31 de agosto de 2012, realizou-se audiência pública (Youtube, 2012a) por determinação do Ministro Relator Marco Aurélio Mello. Foram ouvidas 35 pessoas acerca das implicações da produção e uso do amianto para a saúde humana e também para o interesse da economia e do mundo do trabalho.

Nessa ocasião, o depoimento do médico Ubiratan de Paula Santos (Youtube, 2012b) reforçou as conclusões do CIRC publicadas no mesmo ano de 2012, no sentido de que o amianto crisotila é comprovadamente cancerígeno. Lembrou o médico que $90 \%$ do amianto que se consume no 156 mundo é o crisotila. Desse modo, não teria nenhuma lógica satisfazer-se com a proibição dos demais tipos de amianto que, à evidência, dada a quantidade de consumo, não são os responsáveis pela totalidade dos números mundiais da doença. Na mesma ocasião, o médico Marcos Sabino reforçou que o uso do amianto é causador de elevado índice de morbidade. Ele rebateu veementemente a tese de que com a adoção de medidas de controle, a partir de 1980, os problemas estariam sob controle e que os casos existentes seriam remanescentes de uma época em que o amianto era usado de forma indiscriminada. No entanto, o Ministro Marco Aurélio de Melo, ao proferir seu voto (STF, 2012a), em 30 de outubro de 2012, disse não haver "indicação de que o amianto seja mais perigoso do que outras substâncias como o tabaco, o álcool e o benzeno" e que, mais, não se poderia proibir um produto pela via judicial. Além disso, não haveria incompatibilidade entre a lei federal e a Convenção 162 da OIT, que não proíbe o uso do amianto crisotila. 
Proibir completamente o seu uso, segundo o ministro, provocaria um grave problema econômico que uma Corte Suprema deve evitar. Mantendo a posição que adotou no voto apresentado na ADI n ${ }^{\circ} 3.357$, o Ministro Ayres Britto votou pela improcedência da ADI.

Apenas em 2 de abril de 2008, a Associação Nacional dos Procuradores do Trabalho (ANPT) e a Associação dos Magistrados Trabalhistas (Anamatra) promoveram a ADI $\mathrm{n}^{\circ} 4.066$ (STF, 2008), questionando a constitucionalidade do artigo $2^{\circ}$ da Lei $\mathrm{n}^{\circ} 9.055 / 95$, que estabelece a possibilidade da exploração e uso do amianto crisotila no Brasil. Embora tenha sido requerida a suspensão liminar da aplicação do dispositivo citado, até a presenta data ela não foi analisada, tampouco decidida.

Embora o julgamento das duas primeiras demandas tenha sido iniciado há mais de três anos, e o da terceira há oito anos, não há indicação de data no histórico desses processos (STF, 2004) para a continuidade ou início de julgamento, respectivamente. Evidentemente que, à luz da teoria e do sistema constitucional brasileiro e dos compromissos convencionais, o voto do Ministro Marco Aurélio de Mello na $\mathrm{ADI} n^{\circ} 3.739$ é, no mínimo, equivocado. Faz parte das atribuições de uma Corte Constitucional - aliás, esta é a principal razão de sua existência - julgar a inconstitucionalidade de leis ordinárias e, para tanto, invariavelmente é conduzida a realizar análises substanciais que envolvem conhecimentos específicos. Justamente para munir a Corte Suprema de argumentos para enfrentar situações desse jaez é que o legislador criou a figura da audiência pública. A integral substancialização desse instituto, relativamente novo nas práticas processuais do Brasil, somente acontecerá se o conteúdo das manifestações orais repercutirem no conteúdo das decisões dos juízes. É preciso registrar também que as instâncias ordinárias da jurisdição trabalhista têm decidido contrariamente às empresas que fazem uso do amianto. Instituições como o 
Ministério Público do Trabalho (MPT) vêm concentrando esforços para banir o uso em todas as suas extensões pela via de ações civis públicas, que exigem indenização aos trabalhadores que tiveram contato com o amianto por irregularidades no ambiente de trabalho.

Dentre as ações civis públicas, destaca-se a ajuizada pelo MPT em São Paulo contra a empresa Eternit - que, desde 2013, estava suspensa em caráter liminar pelo Ministro Celso de Mello por examinar a Reclamação (RCL) da Eternit, que questionava as ações. No entanto, o Procurador-Geral da República Rodrigo Janot emitiu parecer em agravo regimental da Abrea, derrubando todos os argumentos apresentados pela empresa. Em seu julgamento final, o ministro aceitou o parecer de Janot. Sendo assim, a despeito de todos os esforços da Eternit em procrastinar o feito, segue ativo o pedido de condenação em 1 bilhão de reais por danos (notadamente reparação transindividual) que teriam 158 sidos causados a ex-empregados de uma fábrica em Osasco (SP), cidade onde a empresa manteve planta industrial por 52 anos (MPT, 2016).

Houve também uma importante ação ajuizada pelo MPT de Santa Catarina após a loja de material de construção Dal Mas \& Amaral Ltda. se negar a firmar TAC para tomar medidas necessárias de proteção aos empregados expostos ao produto. A loja foi condenada a encaminhar anualmente ao Sistema Único de Saúde (SUS) e ao sindicato profissional uma listagem de empregados expostos e ex-expostos ao asbesto/amianto, com avaliação médica e diagnóstico de radiografias de tórax para identificar pneumoconioses, realizar exames médicos de controle dos trabalhadores durante trinta anos. A Dal Mas \& Amaral também deverá fornecer gratuitamente equipamentos de proteção individual (EPIs) adequados ao risco, como proteção respiratória e roupas específicas para o manuseio do produto. Deve ainda controlar a emissão de poeira do amianto no 
estabelecimento e eliminar os resíduos, que contêm asbesto, sem gerar risco à saúde dos trabalhadores e da população em geral (MPT, 2016).

Experiências comparadas podem indicar se o sistema jurídico-processual brasileiro está no caminho das respostas mais adequadas para não só banir definitivamente o amianto quanto para reparar toda sorte de danos causados à saúde e ao meio ambiente.

\section{Os exemplos francês e italiano}

Se, no Brasil, o contencioso relativo ao amianto está focado no sistema de controle concentrado e abstrato da constitucionalidade, tanto quanto em demandas coletivas promovidas pelo Ministério Público do Trabalho, o estado da questão na França e na Itália obedece a uma lógica um pouco diferenciada e da qual o sistema judiciário brasileiro poderá tomar interessantes lições. É revelador que, até o presente momento, o contencioso do amianto não aportou aos foros da justiça penal brasileira, ainda que o artigo 278 do Código Penal (CP) esteja em vigor ${ }^{9}$, bem como a Lei $\mathrm{n}^{\circ} 9.605 / 98$, que regula os crimes ambientais.

Na França, a década de 1990 foi marcada pelo escândalo do amianto, que eclodiu com o prognóstico de que até o ano de 2025 haveria em torno de 100 mil mortes em decorrência da exposição ao mineral, seja por razões profissionais ou ambientais. O reconhecimento dos danos de massa levou o legislador francês a criar dois fundos para viabilizar as indenizações, o FCAATA em 1999 e o FIVA em 2002 (Keim-Bagot, 2016).

No ano de 2002, a Corte de Cassação francesa proferiu inúmeras decisões em ações de indenização cujo conteúdo

\footnotetext{
9 Espécie de crime contra a saúde pública: "Fabricar, vender, expor à venda, ter em depósito para vender ou, de qualquer forma, entregar a consumo coisa ou substância nociva à saúde, ainda que não destinada à alimentação ou a fim medicinal.”
} 
causou enorme impacto no direito de acidentes do trabalho. Moraine Keim-Bagot destaca que a profunda transformação nesse ramo do direito adveio da compreensão daquela alta Corte de que os empregadores faltaram com a sua obrigação de "segurança". Os casos relativos ao amianto foram o ponto de partida de uma verdadeira metamorfose da reparação em matéria de risco profissional e levaram à afirmação do direito do trabalhador à proteção efetiva de sua saúde em direito do trabalho e, portanto, além do direito da seguridade social. Porém, lembra a autora, que "a complexa cadeia de responsabilidades individuais que levaram a uma tal catástrofe sanitária não foi elucidada" (Keim-Bagot, 2016, p. 309). Se a justiça reconheceu a responsabilidade do Estado por omissão, as vítimas não lograram obter junto à justiça francesa o reconhecimento da responsabilidade dos empregadores, notadamente no campo penal, ao contrário da posição tomada pela justiça de Turim, na Itália, comentada a 160 seguir. A autora coloca em evidência a inadaptação da legislação penal francesa às catástrofes sanitárias (Keim-Bagot, 2016, p. 310). Dentre os obstáculos levantados, podem ser mencionados a questão do tempo (doenças que se manifestam dezenas de anos mais tarde) não somente por suas implicações em termos de prescrição, mas também por dificultar a identificação dos responsáveis pelo desaparecimento das empresas, dos empregadores e das vítimas.

Tal inadaptação, somada à inação estatal muito específica, uma vez que o Ministério Público jamais apresentou qualquer denúncia ${ }^{10}$, bem serviu aos propósitos empresariais de isentar-se de responsabilidade. Esse acanhamento, segundo a autora citada, é muito peculiar às catástrofes sanitárias, mas que, no caso do amianto, assumiu características particulares

\footnotetext{
${ }^{10}$ É preciso ressaltar que, na França, vigora o princípio da oportunidade da ação penal, e que existe um vínculo de dependência entre o Ministério Público e o Ministério da Justiça. A iniciativa de acionamento da justiça penal na França foi proveniente das associações de vítimas.
} 
em face da "colusão" (Keim-Bagot, 2016, pp. 312-13) entre os órgãos públicos e os empresários do amianto. Resta, desse modo, que, no plano penal, Estado e empresas jogaram uns contra os outros a culpa e, ao final, nenhum desses atores assumiu qualquer responsabilidade pelo desastre do amianto. Em 2015, passados quase vinte anos do início do processo penal, as vítimas voltaram à estaca zero (Le Monde, 2015).

No plano civil, a condição das vítimas também restou sofrível porque os empresários apenas de modo muito marginal foram demandados. A existência dos fundos antes citados, em vez de melhorar a condição das vítimas, produziu o espectro de uma responsabilidade coletiva que viabilizou indenizações rápidas e quase automáticas, e, com isso, esvaziou a busca de responsabilidades individuais. Na mesma senda, embora o Estado francês fosse responsável por "falta” ou omissão, os fundos de indenização das vítimas só vieram a confirmar a frágil responsabilidade estatal.

É evidente, por qualquer ângulo que se analise o caso francês, a inadaptação dos regimes de responsabilidades diante dos imensos danos causados pela produção e uso do amianto, que, segundo Keim-Bagot (2016, pp. 316-17), deve servir de "alerta no plano internacional", pois a chancela do uso do amianto, ainda hoje, oculta a profunda tragédia humana e ambiental que vitimiza muitas vidas humanas.

Já o caso italiano, que se limitou ao âmbito penal, trouxe esperanças de uma responsabilização, em um contexto de globalização, dos detentores do poder econômico e das decisões implicando violações do direito à saúde. E isso decorreu da atuação do Ministério Público italiano, que, de maneira similar ao Brasil e em oposição à situação francesa, goza de independência funcional, uma vez que não está vinculado ao Poder Executivo. Desse modo, segundo Luca D'Ambrosio (2016, p. 320), por realizar a "gestão política" dos conflitos e por levar em conta o "direito vivo" é que a matéria foi objeto de denúncia por parte do Ministério Público italiano em Turim. 
Conhecido como o "escândalo Eternit" (Les Echos, 2014), ele pode ser considerado um caso paradigmático de repressão penal de riscos industriais. A situação muito particular dessa demanda penal é que, escapando da motivação clássica ancorada na culpa e no resultado, o agente do Ministério Público denunciou os dirigentes da Eternit por atos atentatórios à segurança pública. Além disso, o caso inova ao tomar em consideração os relatórios epidemiológicos como elemento de prova das infrações.

De fato, o Ministério Público de Turim, nesse caso, efetivamente quebrou a tradição das denúncias em matéria de riscos industriais, por ter usado como fundamento a existência de delito contra a segurança pública, qualificado pela "omissão às obrigações de prevenção de desastres ou de acidentes do trabalho", bem como de "desastre ambiental" (D’Ambrosio, 2016). No âmbito particular deste último, a prova da materialidade dessa infração decorreu da demons162 tração de uma contaminação "excepcional" do meio ambiente em razão da produção do amianto. Decorreu também da comprovação do risco concreto à saúde de indivíduos e grupos, fato que os estudos epidemiológicos comprovaram.

O essencial do caso italiano "Eternit" foi ter a justiça estabelecido a virada paradigmática do direito penal da causalidade para o direito penal do risco, e que a inserção da violação da segurança jurídica no âmbito do processo penal permitiu garantir uma proteção penal mais efetiva à vida e à saúde humanas.

No entanto, apesar da condenação penal dos dirigentes da Eternit, mais tarde reformada pelos juízes da Corte de Cassação da Itália pelo reconhecimento da prescrição (D'Ambrosio, 2016, p. 340), o caso ainda apresentou relevantes aspectos na perspectiva do direito das vítimas. A questão principal era a de saber se a incriminação dos dirigentes poderia responder "à catástrofe humana, sanitária e ambiental" causada pela produção do amianto, sobretudo 
com relação às consequentes doenças e mortes causadas (D’Ambrosio, 2016, p. 335).

De fato, os casos de desastres industriais apresentam uma dupla face: aquela que se relaciona às ofensas à segurança coletiva e outra que se relaciona à vida e à saúde do homem individualmente considerado. Assim, para D'Ambrosio, se o processo penal de Turim trouxe repercussões positivas para as ofensas à segurança coletiva, não foi o que aconteceu com o direito das vítimas, não alcançadas pela proteção penal. Além disso, a justiça italiana não reconheceu às vítimas reparação por "dano de exposição" (p. 336) e a Corte de Apelação de Turim fez uma clara opção: ainda que tenha confirmado a condenação dos dirigentes por desastre ambiental, tal decisão despersonalizou o prejuízo, e, de maneira mais preocupante, minimamente individualizou os prejuízos comuns das vítimas, independentemente da natureza e extensão dos danos sofridos (p. 338).

Os dois casos indicam as fragilidades ainda persistentes dos modelos de justiça formados no paradigma individualista, por não apresentarem respostas aos problemas jurídicos de dupla face: individuais e coletivos simultaneamente. E o caso italiano, particularmente, evidencia o risco, como afirma D’Ambrosio (2016, p. 339) à imposição de condenações penais e indenizações apenas "simbólicas".

Os exemplos analisados neste artigo mostram os limites das respostas nacionais ou locais aos casos complexos condizentes à exploração e utilização do amianto. Uma transformação do direito é necessária em face dos riscos globais que desestabilizam a lógica jurídica tradicional, já que impõem uma lógica de antecipação dos danos.

$* * *$

Se a utilidade do amianto para a produção de mercadorias e sua importância para a economia global são os dois principais 
argumentos apresentados por aqueles que defendem seu "uso controlado", os riscos que apresenta e os danos que efetivamente causam à vida, à saúde humana e ao meio ambiente são infinitamente maiores. Justamente por isso é que sua produção e consumo estão centrados nos ditos países "em desenvolvimento", que, já tradicionalmente, se submetem aos interesses financeiros dos mais ricos e poderosos.

Como foi possível aferir, há, no entanto, instituições nacionais e não nacionais que apresentam resistência ao uso do amianto, a exemplo da Abrea, no Brasil, que fundamenta sua luta no último relatório da OMS, o qual garante não haver um limite seguro de utilização desse material. De forma paralela, empresas que se beneficiam de sua extração continuam a defender, baseadas em pesquisas taticamente selecionadas, o uso controlado - controlado pela impávida busca do lucro.

Os inegáveis comprometimentos internos assumidos 164 pelos governantes e pelos legisladores os mantêm atrelados à "mão invisível” do mercado, que, evidentemente, não intenta libertá-los. Resta ao Poder Judiciário a responsabilidade de decidir sobre essas questões, levando em conta, acima de tudo, o direito a uma vida digna e saudável. Delmas-Marty (2013) nos ensina que o papel do direito diante dos paradoxos da mundialização se assegura em três verbos: resistir, responsabilizar e antecipar. Resistir ao processo de desumanização trazido pela mundialização, responsabilizar os titulares de poder e antecipar os riscos futuros. Mas lembremos: o ritmo e as respostas que os sistemas de justiça têm dado a tais demandas dependem da complexidade do sistema processual e da estrutura da própria justiça.

Enquanto, no Brasil, os contenciosos concentram-se em questões de foro constitucional, e, na França, a responsabilização dos empregadores foi débil - visto que a demandas não foram penais -, a Itália se diferencia por tratar da problemática unicamente na esfera do direito penal, que, 
de igual modo, apresentou fragilidades. A respeito disso, os casos citados desmascaram os vieses dos modelos de justiça formados no paradigma individualista por não tratarem dos problemas individuais e coletivos conjuntamente.

Mesmo que, teoricamente, as jurisdições nacionais devam estar aptas a tratar do caso amianto e considerar sua produção e consumo violação aos direitos humanos, uma vez que a maioria dos países inserem na sua carta constitucional o direito à saúde e o direito ao meio ambiente saudável no rol dos direitos humanos ou dos direitos fundamentais, suscita-se a possibilidade de inserir tais direitos no que se compreende por jus cogens internacional.

Nossos trabalhos futuros promoverão a análise prospectiva sobre as respostas provenientes do direito internacional, notadamente dos sistemas de proteção dos direitos humanos, através de uma interpretação extensiva e dinâmica de seus textos fundadores, capazes de afirmar a indivisibilidade desses direitos, apagando, assim, a velha separação entre, de um lado, direitos civis e políticos, de outro, direitos sociais, econômicos e culturais (Martin-Chenut, 2016). Outrossim, tal atividade hermenêutica pode contribuir para o reequilíbrio de responsabilidades entre Estados e atores econômicos privados por violações de direitos humanos.

\section{Kathia Martin-Chenut}

é pesquisadora do CNRS (Centre National de la Recherche Scientifique), França, UMR DRES (CNRS/Unistra) Equipe RSE.

\section{Jânia Saldanha}

é professora da graduação e pós-graduação do Departamento de Direito e da Universidade Federal de Santa Maria (UFSM), Rio Grande do Sul. 


\section{Bibliografia}

ABREA - Associação Brasileira dos Expostos ao Amianto. 2015. [on-line]. Disponível em: <http://www.abrea.org.br/>. Acesso em: 14 abr. 2016. 2011. Banimento do amianto no Brasil. Tabela atualizada com legislação até 2011. Disponível em: <http:/ / www.abrea.com.br/ QUADRO\%20ATUAL\%20banimento.htm>. Acesso em: 14 abr. 2016. ANDEVA - Association Nationale de Défense des Victimes de l'Amiante. 2014. [on-line]. International - Canadá. Disponível em: <http:/ / andeva.fr/?-Canada->. Acesso em: 14 abr. 2016.

2015. [on-line]. Amériques (hors Canada). Disponível em: <http://andeva.fr/?-Amerique-du-sud->. Acesso em: 14 abr. 2016.

BRASIL. 1988. Constituição da República Federativa do Brasil, de 5 de outubro de 1988. Disponível em: <http://www.planalto.gov.br/ccivil_03/ Constituicao/ConstituicaoCompilado.htm>. Acesso em: 10 maio 2016. 1991. Decreto ${ }^{\circ} 126$, de 22 de maio. Promulga a Convenção $n^{\circ}$ 162, da Organização Internacional do Trabalho - OIT, sobre a Utilização do Asbesto com Segurança. Disponível em: <http:/ /www.planalto.gov. br/ccivil_03/decreto/1990-1994/d0126.htm>. Acesso em: 14 abr. 2016. 1995. Lei $\mathrm{n}^{\circ} 9.055$, de $1^{\circ}$ de junho. Disciplina a extração, industrialização, utilização, comercialização e transporte do asbesto/ amianto e dos produtos que o contenham, bem como das fibras naturais e artificiais, de qualquer origem, utilizadas para o mesmo fim e dá outras providências.

1998. Lei $\mathrm{n}^{\circ} 9.605$, de 12 de fevereiro. Dispõe sobre as sanções penais e administrativas derivadas de condutas e atividades lesivas ao meio ambiente, e dá outras providências. Disponível em: <http:/ /www. planalto.gov.br/ccivil_03/leis/L9605.htm>. Acesso em: 20 jul. 2016. 2014. Portaria Interministerial $n^{\circ} 9$, de 7 de outubro. Disponível em: <http://www.abrea.com.br/PORTINTERMINISTERIAL.jpg>. Acesso em: 14 abr. 2016.

BRUM, E.; CANÇADO, P.; BARROCAL, A. 2005. Vida e morte. Revista Época. Rio de Janeiro, n. 360, pp. 10-13. Disponível em: <www.abrea.org.br >. BUREAU International Du Travail. Conseil d'Administration. 2006. Troisième question à l'ordre du jour. Disponível em: <http:/ /www.ilo.org/ public/french/standards/relm/gb/docs/gb297/pdf/gb-3-1.pdf>. Acesso em: 14 abr. 2016.

CANADÁ. 2015. [governo do Canadá on-line, atual. 19 jun.]. Risques pour la santé associés à l'amiante. Disponível em: <http:/ / canadiensensante. gc.ca/healthy-living-vie-saine/environment-environnement/air/ contaminants/asbestos-amiante-fra.php>. Acesso em: 14 abr. 2016. 
CASTELLS, M. 2007. A era da informação: economia, sociedade e cultura. In: . A sociedade em rede. São Paulo: Paz e Terra. Vol. 1

CASTRO, H.; GIANNASI, F.; NOVELLO, C. 2003. A luta pelo banimento do amianto nas Américas: uma questão de saúde pública. Ciências $\mathcal{E}$ ? Saúde Coletiva, v. 8, n. 4. Disponível em: <http://www.scielo.br/scielo. php? script=sci_arttext\&pid=S1413-81232003000400013\&lng=pt\&nrm= iso>. Acesso em: 14 abr. 2016.

CENTRO Colaborador UFBA/ISC/Pisat. 2012. Boletim Epidemiológico Morbimortalidade de Agravos à Saúde Relacionados ao Amianto no Brasil, 2000 a 2011, ano II, n. 5. Disponível em: <http:/ / renastonline.ensp. fiocruz.br/sites/default/files/arquivos/recursos/bol7_amiantoF9. pdf>. Acesso em: 14 abr. 2016.

CNTI - Confederação Nacional dos Trabalhadores na Indústria. 2007. Petição de Ação Direta de Inconstitucionalidade com pedido de medida cautelar, assinada em 3 de agosto. Disponível em: <http:/ / redir.stf.jus.br/paginadorpub/paginador. jsp?docTP $=\mathrm{TP} \&$ doc $\mathrm{ID}=1563146 \# 0 \% 20-\% 20$ Peticao $\% 20 \mathrm{inicial}>$. Acesso em: 14 abr. 2016.

D’AMBROSIO, L. 2016. L'Affaire italienne Eternit: quelles leçons?. In: MARTIN-CHENUT, K.; QUENAUDON, R. Développement durable: mutations ou métamorphoses de la responsabilité? Paris: Pedone.

DELMAS-MARTY, M. 2004. Por um direito comum. São Paulo: Martins Fontes.

2010. Les forces imaginantes du droit. In: Vers une communauté de valeurs? Paris: Seuil. Vol. IV. 2013. Résister, responsabiliser, anticiper. Paris. Seuil.

DNPM - Departamento Nacional de Produção Mineral. 2014. Sumário mineral. Escrito por Thiers Muniz Lima, Carlos Augusto Ramos Neves. Brasília, DF: DNPM. Disponível em: <http://www.dnpm.gov. $\mathrm{br} / \mathrm{dnpm} /$ sumarios/sumario-mineral-2014>. Acesso em: 14 abr. 2016.

ECODEBATE. 2015, 17 dez. Empresas se comprometem a banir o amianto até 2017. Disponível em: <https://www.ecodebate.com. br/2015/12/17/empresas-se-comprometem-a-banir-o-amiantoate-2017/>. Acesso em: 14 abr. 2016.

EL PAÍS. 2014, 1 nov. México sigue importando amianto, prohibido en más de 50 países. Escrito por Laura Delle Femmine. Disponível em: <http://internacional.elpais.com/internacional/2014/10/01/ actualidad/1412197454_661881.html>. Acesso em: 14 abr. 2016.

FARIA, J. E. 2004. O direito na economia globalizada. São Paulo: Malheiros. 
FRANÇA. Decreto nº 96-1133, de 24 de dezembro de 1996, relativo à interdição do amianto, em aplicação do Código do Trabalho e Código do Consumidor. Disponível em: <https://www.legifrance.gouv.fr/ affichTexte.do;jsessionid=6D1768A7602488565A83545E6FBC1516.tpd ila08v_3?cidTexte=JORFTEXT000000734637\&dateTexte=19961226 $>$. Acesso em: 16 abr. 2016.

Sénat. 2005. Rapport d'information fait au nom de la mission commune d'information sur le bilan et les conséquences de la contamination par l'amiante, n. 37 (2005-2006). Disponível em: <http://www.senat.fr/rap/r05-0371/r05-037-120.html\#toc109>. Acesso em: 14 abr. 2016.

2012. Interdiction de l'amiante en Europe et dans le monde, $14 \mathrm{e}$ législature. Disponível em: <http://www.senat.fr/questions/ base/2012/qSEQ12110252S.html>. Acesso em: 14 abr. 2016.

GIANNASI, F. 2002. A construção de contrapoderes no Brasil na luta contra o amianto: a globalização por baixo. Disponível em: <www.abrea. org.br>.

IARC Monographs. 2012. Asbestos (chrysolite, amosite, crocidolite, tremolite, actinolite and anthophyllite). Disponível em: <http://monographs.iarc.fr/ENG/ Monographs/vol100C/mono100C-11.pdf>. Acesso em: 14 abr. 2016. . 2015. Agents Classified by the IARC Monographs. Vols. 1-116.

168 Disponível em: <http://monographs.iarc.fr/ENG/Classification/ ClassificationsAlphaOrder.pdf $>$. Acesso em: 14 abr. 2016.

IBC - Instituto Brasileiro de Crisotila. 2014, 17 set. Riscos à saúde decorrentes da crisotila. Disponível em: <http://www.ibcbrasil.org.br/pesquisa/riscosa-saude-decorrentes-da-crisotila>. Acesso em: 14 abr. 2016.

. 2016. [on-line]. Disponível em: <http://www.ibcbrasil.org.br/ quem-somos-institucional>. Acesso em: 14 abr. 2016.

IDEC - Instituto Brasileiro de Defesa do Consumidor. 2007, 21 fev. Idec e Conselho Nacional de Saúde apoiam trabalhadores expostos ao amianto. Disponível em: <http://www.idec.org.br/em-acao/em-foco/idece-conselho-nacional-de-saude-apoiam-trabalhadores-expostos-aoamianto>. Acesso em: 14 abr. 2016.

INCA - Instituto Nacional do Câncer. 2016. [on-line]. Câncer: prevenção e fatores de risco. Amianto. Disponível em: <http:/ /www2.inca.gov.br/ $\mathrm{wps} / \mathrm{wcm} /$ connect/cancer/site/prevencao-fatores-de-risco/amianto $>$. Acesso em: 14 abr. 2016.

KEIM-BAGOT, M. 2016. Dix ans après les arrêts "amiante": le point sur les responsabilités en matière de maladies professionnelles. In: MARTINCHENUT, K.; QUENAUDON, R. Développement durable: mutations ou métamorphoses de la responsabilité? Paris: Pedone. 
LE MONDE. 2015, 17 avril. Amiante: les associations de victimes dénoncent le "choix de protéger les décideurs". Ecrit par Francine Aizicovici. Disponível em: http:/ / www.lemonde.fr/economie/ article/2015/04/17/amiante-les-associations-de-victimes-denoncent-lechoix-de-proteger-les-decideurs_4618187_3234.html >. Acesso em: 14 abr. 2016.

LES ECHOS. 2014, 20 nov. Scandale Eternit: le verdict de la Cour de cassation provoque la colère en Italie. Ecrit par Pierre De Gasquet. Disponível em: http:/ /www.lesechos.fr/20/11/2014/lesechos. fr/0203953551948_scandale-eternit-le-verdict-de-la-cour-de-cassationprovoque-la-colere-en-italie.htm\#>. Acesso em: 14 abr. 2016.

MARTIN-CHENUT, K. 2016. Développement durable, juridictions de protection des droits de l'homme et métamorphoses de la responsabilité. In: MARTIN-CHENUT, K; QUENAUDON, R. Développement durable: mutations ou métamorphoses de la responsabilité?. Paris: Pedone.

MARTIN-CHENUT, K.; QUENAUDON, R. 2015. Développement durable: mutations ou métamorphoses de la responsabilité? Paris: Pedone.

MPT - Ministério Público do Trabalho. 2015, 5 maio. MPT recebe prêmio "Tribute of Inspiration". Disponível em: <http://radio.mpt.gov.br/ wps/portal/portal_mpt/mpt/sala-imprensa/banco-imagens/>. Acesso em: 14 abr. 2016.

2016. [on-line MPT Notícias]. Disponível em: <http://portal.mpt. $\mathrm{mp} . \mathrm{br} / \mathrm{wps} /$ portal/portal_mpt/mpt/sala-imprensa/mpt-noticias/>. Acesso em: 14 abr. 2016.

OMS - Organização Mundial da Saúde. 2014. Chrysotile Asbestos. Disponível em: <http://www.who.int/ipcs/assessment/public_health/chrysotile_ asbestos_summary.pdf $>$. Acesso em: 14 abr. 2016.

. 2016. [on-line]. Programme international sur la sécurité des substances chimiques: Amiante. Disponível em: <http://www.who.int/ipcs/ assessment/public_health/asbestos/fr/>. Acesso em: 14 abr. 2016.

SALDANHA, J.; BLATT, P. 2007. O caso amianto: conjuntura internacional e jurisprudência do STF. Revista Eletrônica do Curso de Direito da UFSM, v. 2, n. 3. Disponível em: <http://cascavel.ufsm. $\mathrm{br} /$ revistas/ojs-2.2.2/index.php/revistadireito/article/view/6816\#. VtwJuvkrLIU>. Acesso em: 14 abr. 2016.

SANTÉ Canada juge l'amiante plus dangereux qu'avant. 2015, 2 juil. ICI Radio-Canada. Disponível em: <http://ici.radio-canada.ca/nouvelles/ societe/2015/07/02/001-amiante-sante-canada-changement-position. shtml>. Acesso em: 14 abr. 2016. 
SANTOS, B. de S. 2006. A gramática do tempo: para uma nova cultura política. São Paulo: Cortez.

STF - Supremo Tribunal Federal. 2003a. Ação Direta de

Inconstitucionalidade $\mathrm{n}^{\circ}$ 2.396-9, julgada em 8 de maio de 2013.

Disponível em: $<$ http://redir.stf.jus.br/paginadorpub/paginador. jsp?docTP=AC\&docID=375387>. Acesso em: 14 abr. 2016.

. 2003b. Ação Direta de Inconstitucionalidade $n^{\circ}$ 2.656-9, julgada em 8

de maio de 2003. Disponível em: <http:/ / redir.stf.jus.br/paginadorpub/ paginador.jsp?docTP=AC\&docID=266877> . Acesso em: 14 abr. 2016.

2004. Acompanhamento processual da Ação Direta de

Inconstitucionalidade $\mathrm{n}^{\circ} 3.357$, proposta em 30 de novembro de

2004. Disponível em: <http:/ /www.stf.jus.br/portal/processo/

verProcessoAndamento.asp?incidente=2258854>. Acesso em: 14 abr. 2016.

2008. Acompanhamento processual da Ação Direta de

Inconstitucionalidade $\mathrm{n}^{\circ} 4.066$, proposta em 2 de abril de 2008.

Disponível em: <http://www.stf.jus.br/portal/processo/

verProcessoAndamento.asp?incidente=2607856> . Acesso em: 14 abr. 2016. 2012a. Ação Direta de Inconstitucionalidade $n^{\circ} 3.937$. Voto do relator, senhor Ministro Marco Aurélio, proferido em 30 de outubro. Disponível em: <http://www.stf.jus.br/arquivo/cms/noticiaNoticiaStf/ 170 anexo/ADI3937relator.pdf>. Acesso em: 14 abr. 2016.

2012b, 31 out. Ministro Ayres Britto vota pela constitucionalidade de normas que vedam o uso do amianto. Disponível em: $<$ http:/ /www. stf.jus.br/portal/cms/verNoticiaDetalhe.asp?idConteudo=222750 $>$. Acesso em: 14 abr. 2016.

UNICAMP - Universidade Estadual de Campinas. 2010. Avaliação do impacto econômico da proibição do uso do amianto na construção civil no Brasil. Disponível em: <https://inverde.files.wordpress.com/2010/10/ estudo-unicamp-impacto-economico-da-proibicao-do-amianto.pdf $>$. Acesso em: 14 abr. 2016.

VOGEL, L. 2005. L'amiante dans le monde. Dossiê. HESA Newsletter. Disponível em: <http:// www.cancer-environnement.fr/Portals/0/Documents $\% 20$ PDF/Rapport/Autre/HESA/2005_L\%E2\%80\%99amiante\%20dans\%20 le\%20monde.pdf>. Acesso em: 14 abr. 2016.

YOUTUBE. 2012a. Audiência Pública Amianto. 9 vídeos. Disponível em: <https:/ / www.youtube.com/playlist?list=PL8031EED7EAEAF459>. Acesso em: 14 abr. 2016.

. 2012b. Audiência Pública Amianto (4/4). Realizada em 24 agosto de 2012. Disponível em: <https:/ / www.youtube.com/watch?v=mwnVI3nxD No\&list=PL8031EED7EAEAF459\&index=4>. Acesso em: 14 abr. 2016. 


\title{
O CASO DO AMIANTO: OS LIMITES DAS SOLUÇÕES LOCAIS PARA UM PROBLEMA DE SAÚDE GLOBAL
}

\author{
KATHIA MARTIN-CHENUT \\ JÂNIA SALDANHA
}

Resumo: O artigo analisa o tema de saúde pública "glocal" relacionado à produção, distribuição e uso do amianto. A comprovação dos malefícios que esse mineral causa à saúde e ao meio ambiente justifica as proibições nacionais e globais de sua utilização. Por outro lado, a força dos interesses econômicos de grandes empresas exploradoras do amianto estimula muitos Estados a manter a política do uso controlado. Por envolver violação de direitos humanos, o tema foi objeto de judicialização em alguns países, como Brasil, França e Itália, cuja observação comparativa evidencia a assimetria das respostas.

Palavras-chave: Amianto; Saúde Global; Autorização; Proibição; Judicialização; Comparação.

\section{THE CASE OF ASBESTOS: LIMITS OF LOCAL SOLUTIONS TO A GLOBAL HEALTH ISSUE}

Abstract: This article analyzes the "glocal" public health issue related to the production, distribution, and use of asbestos. The evidence regarding the harm of this mineral to the health and environment justifies the national and global prohibitions of its use. However, the strength of economic interests regarding asbestos' great exploration by companies encourages many states to maintain the policy of controlled use. Since in involves the violation of human rights, the issue was an object of judicialization in some countries, such as Brazil, France and Italy, whose comparative observation highlights the asymmetry of responses.

Keywords: Asbestos; Global Health; Authorization; Prohibition; Judicialization; Comparison.

Recebido em: 14/4/2016

Aprovado em: 17/6/2016 